\title{
GMR
}

\section{Role of $I L-8$ rs4073 and rs2227306 polymorphisms in the development of primary gouty arthritis in a Chinese population}

\author{
Y.X. Cui, H. Zhao and H.Q. Guo \\ Department of Rheumatism, Yan'an University Affiliated Hospital, Yan'an, China \\ Corresponding author: Y.X. Cui \\ E-mail: cuiyixia557@126.com
}

Genet. Mol. Res. 15 (4): gmr15048511

Received February 1, 2016

Accepted April 11, 2016

Published October 17, 2016

DOI http://dx.doi.org/10.4238/gmr15048511

Copyright (C) 2016 The Authors. This is an open-access article distributed under the terms of the Creative Commons Attribution ShareAlike (CC BY-SA) 4.0 License.

\begin{abstract}
In this study, we investigated the role of two single nucleotide polymorphisms in the promoter region of the interleukin-8 gene ( $I L-8 ;$ rs4073 and rs2227306) in the susceptibility to primary gouty arthritis in a Chinese population. Three hundred and twelve patients with primary gouty arthritis and 340 healthy controls were recruited from the Yan'an University Affiliated Hospital between January 2014 and March 2015. The $I L-8$ rs4073 and rs2227306 polymorphisms were genotyped by polymerase chain reaction combined with restriction fragment length polymorphism. Unconditional multiplelogistic regression analysis revealed that the TT genotype of rs4073 was correlated with primary gouty arthritis risk, compared to the AA genotype [adjusted odds ratio $(\mathrm{OR})=1.65,95 \%$ confidence interval $(\mathrm{CI})=1.08-2.54 ; \mathrm{P}=0.02]$. In addition, the $I L-8$ rs $4073 \mathrm{~T}$ allele was associated with a significant elevated risk of primary gouty arthritis, in comparison to the A allele $(\mathrm{OR}=1.34,95 \% \mathrm{CI}=1.07-1.67 ; \mathrm{P}=0.01)$. However, we observed no significant relationship between the $I L-8$
\end{abstract}

Genetics and Molecular Research 15 (4): gmr15048511 
rs2227306 polymorphism and primary gouty arthritis risk. The results of this study suggest that the $I L-8$ rs 4073 polymorphism could be a marker for primary gouty arthritis development.

Key words: $I L-8$; rs4073; rs2227306; Primary gouty arthritis; Polymorphism

\section{INTRODUCTION}

Primary gouty arthritis is a human gouty arthritis with various clinical features, including increased uric acid salt and monosodium urate crystal deposition in the joint capsule, slippery bursa, cartilage, bone, and other tissues, which leads to arthritis, soft tissue mass, development of kidney stones, and urate nephropathy (Baker and Schumacher, 2010; Richette and Bardin, 2010). Several reports have suggested an increase in the morbidity rate of primary gouty arthritis, with a rate of $1.14 \%$ in China (Miao et al., 2008). The development of primary gouty arthritis involves multifactorial processes, and has many associated risk factors, including genetic, environmental, and lifestyle factors (Miao et al., 2008; Weaver, 2008). Recent studies have reported that genetic factors, including $A B C G 2, S L C 2 A 9, N L R P 3$, Toll-like receptor 4, and estrogen receptor gene, play an important role in the susceptibility to gouty arthritis (Huang et al., 2006; Qing et al., 2013; Cai et al., 2014; Kim et al., 2015; Wang et al., 2015).

IL-8 is a key neutrophil chemokine and an effective angiogenic factor. Polymorphisms in $I L-8$ influence the structure, expression, and quantity of IL-8, ultimately affecting the function of genes. So far, no study has reported the relationship between polymorphisms in $I L-8$ and the development of primary gout arthritis. In this study, we investigated the effect of two promoter SNPs in $I L-8$ (rs4073 and rs2227306) on the susceptibility to primary gouty arthritis in a Chinese population.

\section{MATERIAL AND METHODS}

\section{Subjects}

Three hundred and twelve patients with primary gouty arthritis were recruited from the Yan'an University Affiliated Hospital between January 2014 and March 2015. Primary gouty arthritis was diagnosed according to the 1977 criteria of the American College of Rheumatology (ACR) classification (Wallace et al., 1977). Patients with a history of other endocrine diseases, or other autoimmune diseases were excluded from this study.

Data regarding the general characteristics of the study participants were collected from medical records or by a structured questionnaire filled by a face-to-face interview with trained doctors. The demographic, lifestyle, and clinical characteristics of study subjects included the age, gender, tobacco smoking, alcohol drinking, body mass index, hypertension, blood glucose level, triglyceride level, total cholesterol level, urea nitrogen level, and creatinine and uric acid levels.

A total of 340 healthy controls were recruited from the Yan'an University Affiliated Hospital during the same period of time. The control subjects were confirmed to be free of

Genetics and Molecular Research 15 (4): gmr15048511 
primary gouty arthritis and endocrine diseases. The study was approved by the Ethics Committee of Yan'an University Affiliated Hospital. Informed consent was obtained from all subjects.

\section{Genotyping}

Peripheral blood samples were collected from all patients in vacuum tubes containing $5 \%$ EDTA. Genomic DNA was extracted using a DNA purification kit (Tiangen Biotech, Beijing, China) according to the manufacturer instructions. The $I L-8$ rs 4073 and rs 2227306 polymorphisms were genotyped by polymerase chain reaction (PCR) combined with restriction fragment length polymorphism. The forward and reverse primers for $I L-8$ rs 4073 were 5'-TTCTAACACCTGCCACTCTAG-3' and 5'-CACCAAATTGTGGAGCTTCAG-3', respectively, and the forward and reverse primers for $I L-82227306$ were 5'-GGTGAGCACTACCTGACTAGC-3' and 5'-CCACGTCACTGTGACCTAGG-3', respectively. The PCR conditions were set as follows: initial denaturation at $94^{\circ} \mathrm{C}$ for $10 \mathrm{~min}$; 35 cycles of denaturation at $94^{\circ} \mathrm{C}$ for $60 \mathrm{~s}$, annealing at $55^{\circ} \mathrm{C}$ for $30 \mathrm{~s}$, and extension at $72^{\circ} \mathrm{C}$ for $30 \mathrm{~s}$; and a final extension at $72^{\circ} \mathrm{C}$ for $10 \mathrm{~min}$. The AseI and EcoRI restriction enzymes were used for $I L-8$ rs 4073 and rs2227306, respectively. The digested PCR products of $I L-8$ rs 4073 and rs 2227306 were confirmed by $3 \%$ agarose gel electrophoresis, and were observed under ultraviolet light.

\section{Statistical analysis}

The differences in the demographic, lifestyle, and physical characteristics between patients with primary gouty arthritis and control subjects were analyzed by the chi-square test or the Student $t$-test. The association between the $I L-8$ rs 4073 and rs2227306 polymorphisms and the risk of primary gouty arthritis was tested using the odds ratio (OR) and its $95 \%$ confidence intervals $(95 \% \mathrm{CI})$, by considering the common genotype (TT for both rs 4073 and rs2227306) as the reference group. The conformance of the $I L-8$ rs4073 and rs2227306 genotype frequencies with the Hardy-Weinberg equilibrium was determined using the goodness-of-fit chi-square test. The association was considered to be statistically significant when P values were less than 0.05. The SPSS software v.16.0 platform (SPSS Inc., Chicago, IL, USA) was used for all data analysis.

\section{RESULTS}

General information of patients with primary gouty arthritis and control subjects is summarized in Table 1 . The chi-square test or the $t$-test revealed that patients with gouty arthritis were more likely to be males $\left(\chi^{2}=11.33, \mathrm{P}=0.001\right)$, with a higher $\mathrm{BMI}(t=3.98, \mathrm{P}<$ $0.001)$ and higher blood glucose $(t=5.18, \mathrm{P}<0.001)$, triglyceride $(t=5.98, \mathrm{P}<0.001)$, urea nitrogen $(t=4.76, \mathrm{P}<0.001)$, and uric acid $(t=20.11, \mathrm{P}<0.001)$ levels, lower creatinine $(t=$ $3.11, \mathrm{P}=0.001)$ levels, and likely to be suffering from hypertension $\left(\chi^{2}=25.95, \mathrm{P}<0.001\right)$, compared to the control subjects. However, the age $\left(\chi^{2}=1.16, \mathrm{P}=0.12\right)$, alcohol drinking status $\left(\chi^{2}=0.98, \mathrm{P}=0.32\right)$, tobacco smoking status $\left(\chi^{2}=1.69, \mathrm{P}=0.19\right)$, and total cholesterol level $(t=0.31, \mathrm{P}=0.38)$ of patients with primary gouty arthritis did not differ significantly from those of the control subjects.

Genetics and Molecular Research 15 (4): gmr15048511 
The genotype frequencies of the $I L-8$ rs 4073 and rs 2227306 polymorphisms in patients with primary gouty arthritis and control subjects are presented in Table 2 . The chi-square test revealed a significant difference in the genotype frequencies of the rs 4073 polymorphism between primary gouty arthritis patients and control subjects $\left(\chi^{2}=6.37, \mathrm{P}=0.04\right)$, while the genotype frequencies of rs2227306 did not differ significantly between these groups. However, the genotype distribution of $I L-8$ rs 4073 was not in agreement with the HWE in both patients and controls, while that of rs2227306 conformed to the HWE in both groups.

\begin{tabular}{|c|c|c|c|c|c|c|}
\hline Variables & Patients $(\mathrm{N}=312)$ & $\%$ & Controls $(\mathrm{N}=340)$ & $\%$ & Chi-square test or $t$-test & $P$ value \\
\hline Age (years) & & $52.34 \pm 11.32$ & & $53.42 \pm 12.45$ & 1.16 & 0.12 \\
\hline \multicolumn{7}{|l|}{ Gender } \\
\hline Female & 90 & 28.85 & 141 & 41.47 & & \\
\hline Male & 222 & 71.15 & 199 & 58.53 & 11.33 & 0.001 \\
\hline BMI $\left(\mathrm{kg} / \mathrm{m}^{2}\right)$ & & $24.75 \pm 2.65$ & & $23.86 \pm 3.02$ & 3.98 & $<0.001$ \\
\hline \multicolumn{7}{|l|}{ Hypertension } \\
\hline No & 176 & 56.41 & 256 & 75.29 & & \\
\hline Yes & 136 & 43.59 & 84 & 24.71 & 25.95 & $<0.001$ \\
\hline \multicolumn{7}{|l|}{ Alcohol drinking } \\
\hline No & 246 & 78.85 & 257 & 75.59 & & \\
\hline Yes & 66 & 21.15 & 83 & 24.41 & 0.98 & 0.32 \\
\hline \multicolumn{7}{|l|}{ Tobacco smoking } \\
\hline No & 195 & 62.50 & 229 & 67.35 & & \\
\hline Yes & 117 & 37.50 & 111 & 32.65 & 1.69 & 0.19 \\
\hline Blood glucose level (mM) & & $5.80 \pm 2.45$ & & $4.87 \pm 2.13$ & 5.18 & $<0.001$ \\
\hline Triglyceride level (mM) & & $2.24 \pm 1.78$ & & $1.51 \pm 1.32$ & 5.98 & $<0.001$ \\
\hline Total cholesterol level (mM) & & $4.67 \pm 1.64$ & & $4.71 \pm 1.67$ & 0.31 & 0.38 \\
\hline Urea nitrogen level (mM) & & $5.84 \pm 2.54$ & & $5.05 \pm 1.64$ & 4.76 & $<0.001$ \\
\hline Creatinine level $(\mu \mathrm{M})$ & & $90.12 \pm 41.45$ & & $97.54 \pm 14.26$ & 3.11 & 0.001 \\
\hline Uric acid level $(\mu \mathrm{M})$ & & $536.32 \pm 151.80$ & & $341.37 \pm 90.42$ & 20.11 & $<0.001$ \\
\hline
\end{tabular}

Table 2. Genotype distributions of $I L-8$ rs 4073 and rs 2227306 in the two study groups.

\begin{tabular}{l|c|c|c|c|c|c|c|c|c|c}
\hline$I L-8$ gene & $\begin{array}{c}\text { Patients } \\
(\mathrm{N}=312)\end{array}$ & $\%$ & $\begin{array}{c}\text { Controls } \\
(\mathrm{N}=340)\end{array}$ & $\%$ & $\chi^{2}$ test & P value & \multicolumn{2}{|c|}{ P for HWE } & \multicolumn{2}{c}{ MAF } \\
\hline & & & & & & & Patients & Controls & Controls & Database \\
\hline rs4073 & & & & & & & & & & \\
\hline AA & 76 & 24.36 & 112 & 32.94 & & & & & & \\
\hline AT & 135 & 43.27 & 138 & 40.59 & & & & & & \\
\hline TT & 101 & 32.37 & 90 & 26.47 & 6.37 & 0.04 & 0.02 & 0.001 & 0.4676 & 4.7374 \\
\hline rs2227306 & & & & & & & & & & \\
\hline CC & 139 & 44.55 & 164 & 48.24 & & & & & & \\
\hline CT & 134 & 42.95 & 141 & 41.47 & & & & & & \\
\hline TT & 39 & 12.50 & 35 & 10.29 & 1.26 & 0.53 & 0.45 & 0.57 & 0.3103 & 0.2594 \\
\hline
\end{tabular}

$\mathrm{MAF}=$ minor allele frequency.

As determined by unconditional multiple-logistic regression analysis, individuals carrying the TT genotype of rs 4073 showed elevated risk of primary gouty arthritis compared to those expressing the AA genotype (adjusted $\mathrm{OR}=1.65,95 \% \mathrm{CI}=1.08-2.54 ; \mathrm{P}=0.02$ ) (Table 3). In addition, the $I L-8$ rs4073 T allele was associated with a significantly elevated risk of primary gouty arthritis, compared to the A allele $(\mathrm{OR}=1.34,95 \% \mathrm{CI}=1.07-1.67 ; \mathrm{P}=0.01)$. However, we observed no significant relationship between the $I L-8$ rs 2227306 polymorphism and primary gouty arthritis risk. 
Table 3. Relationship between $I L-8$ rs 4073 and rs 2227306 gene polymorphisms and risk of primary gouty arthritis.

\begin{tabular}{l|c|c|c|c|c|c}
\hline$I L-8$ & $\begin{array}{c}\text { Patients } \\
(\mathrm{N}=312)\end{array}$ & $\%$ & $\begin{array}{c}\text { Controls } \\
(\mathrm{N}=340)\end{array}$ & $\%$ & OR (95\%CI) & P value \\
\hline & & & & & & \\
\hline rs4073 & & & & & & \\
\hline AA & 76 & 24.36 & 112 & 32.94 & 1.0 (Ref.) & - \\
\hline AT & 135 & 43.27 & 138 & 40.59 & $1.44(0.97-2.14)$ & 0.06 \\
\hline TT & 101 & 32.37 & 90 & 26.47 & $1.65(1.08-2.54)$ & 0.02 \\
\hline Allele & & & & & & - \\
\hline A & 287 & 91.99 & 362 & 106.47 & 1.0 (Ref.) & - \\
\hline T & 337 & 108.01 & 318 & 93.53 & $1.34(1.07-1.67)$ & 0.01 \\
\hline rs2227306 & 139 & 44.55 & 164 & 48.24 & 1.0 (Ref.) & - \\
\hline CC & 134 & 42.95 & 141 & 41.47 & $1.12(0.80-1.58)$ & 0.49 \\
\hline TT & 39 & 12.50 & 35 & 10.29 & $1.31(0.77-2.26)$ & 0.29 \\
\hline Allele & & & & & & - \\
\hline C & 412 & 132.05 & 469 & 137.94 & 1.0 (Ref.) & - \\
\hline T & 212 & 67.95 & 211 & 62.06 & $1.14(0.90-1.45)$ & 0.26 \\
\hline
\end{tabular}

${ }^{1}$ Adjusted for gender, body mass index, hypertension, and blood glucose, triglyceride, urea nitrogen, creatinine, and uric acid levels.

\section{DISCUSSION}

Primary gouty arthritis is widely accepted as a multifactorial disease; generally, disease pathogenesis can be promoted by a single dominant mutation resulting in the expression of susceptibility genes. This is the first study investigating the possible impact of the rs 4073 and rs2227306 polymorphic sites of $I L-8$ on primary gouty arthritis risk in a Chinese population. The results of our study revealed that the $I L-8$ rs $4073 \mathrm{~T}$ allele was associated with an elevated risk of primary gouty arthritis.

Urate crystal is an important factor for gouty arthritis and immune response. Uric acid crystals released from the synovial tissues and articular cartilage are consumed by phagocytes in the joint fluid, thereby activating a number of defense mechanisms and triggering a strong immune inflammatory response (Shi et al., 2009). Urate crystals activate NALP3 inflammasomes and caspase-1, promote the secretion of IL-1 $\beta$, induce an inflammatory response, and promote the release of many chemokines and inflammatory cytokines, such as IL-1, IL-6, IL-8, and tumor necrosis factor, into the synovial fluid, consequently resulting in the development of primary gouty arthritis (Urano et al., 2002). IL-8 is a potent recruiter of neutrophils and causes angiogenesis. Previous studies have indicated that the C-reactive protein level is significantly increased during acute inflammation. C-reactive proteins promote the nuclear transfer of nuclear factor- $\kappa \mathrm{B}$ and activate the kinase pathway, thereby inducing $I L-8$ transcription and protein secretion (Wang et al., 2010).

Recent studies have indicated that polymorphisms in $I L-8$ could influence the development of various diseases, including acne vulgaris, glioma, gastric diseases, periodontitis, osteoarthritis, ovarian cancer, and oral cancer, as well as acute pancreatitis (Wang et al., 2013; He et al., 2014; Chen et al., 2015; Hussain et al., 2015; Koensgen et al., 2015; Liu et al., 2015; Ramis et al., 2015). Wang et al. (2013) observed, in a meta-analysis of 1324 patients with oral cancer and 1879 healthy controls, that the AA and AT genotypes of $I L-8$ rs 4073 was correlated with an increased risk of oral cancer in a Caucasian population. On the other hand, He et al. (2014) reported, in a case-control study with 150 osteoarthritis patients and 150 controls, that

Genetics and Molecular Research 15 (4): gmr15048511 
the TT genotype and the T allele of $I L-8$ rs 4073 and rs 2227306 polymorphisms conferred an elevated risk of osteoarthritis. Chen et al. (2015) reported that the $I L-8$ rs 407 polymorphism may be involved in periodontitis susceptibility in Brazilian and Asian populations, while Koensgen et al. (2015) reported a correlation between the TT genotype of $I L-8$ rs2227306 and a higher risk of ovarian cancer. Hussain et al. (2015) hypothesized that elevated IL-8 levels and the $I L-8$ rs 4073 genetic variant may be correlated with acne vulgaris in a Pakistani population and Liu et al. (2015) reported that the AA genotype of the $I L-8$ rs 4073 polymorphism conferred a significantly higher risk of glioma, compared to the TT genotype. On the other hand, Ramis et al. (2015), in a study comprising 151 patients infected with Helicobacter pylori and 76 uninfected individuals, reported that AA genotype of $I L-8$ rs 4073 conferred an increased risk of peptic ulcer disease in the presence of an $H$. pylori infection. These studies indicate that $I L-8$ polymorphisms are associated with the development of autoimmune disease. This is the first report of a correlation between the $I L-8$ rs 4073 and rs 2227306 polymorphisms and susceptibility to primary gouty arthritis in a Chinese population. Further studies are required to confirm the findings of this study.

This study design has one major limitation: the sample size is relatively small, which may decrease the statistical power of any significant differences identified between groups. Further investigations with larger-scale sample sizes are warranted to verify our results.

In conclusion, the results of our study suggested that the TT genotype and T allele of the $I L-8$ rs 4073 polymorphism are associated with increased susceptibility to primary gouty arthritis in a Chinese population, suggesting that this polymorphism could be a marker for primary gouty arthritis.

\section{Conflicts of interest}

The authors declare no conflict of interest.

\section{ACKNOWLEDGMENTS}

We thank the staffs of the Yan'an University Affiliated Hospital, for the great help for collecting blood samples of the subjects.

\section{REFERENCES}

Baker JF and Schumacher HR (2010). Update on gout and hyperuricemia. Int. J. Clin. Pract. 64: 371-377. http://dx.doi. org/10.1111/j.1742-1241.2009.02188.x

Cai Y, Peng YH, Tang Z, Guo XL, et al. (2014). Association of Toll-like receptor 2 polymorphisms with gout. Biomed. Rep. 2: 292-296.

Chen X, Huang J, Zhong L and Ding C (2015). Quantitative assessment of the associations between interleukin-8 polymorphisms and periodontitis susceptibility. J. Periodontol. 86: 292-300. http://dx.doi.org/10.1902/ jop.2014.140450

He Y, Liang X, Wu X, Meng C, et al. (2014). Association between interleukin $8-251 \mathrm{~A} / \mathrm{T}$ and $+781 \mathrm{C} / \mathrm{T}$ polymorphisms and osteoarthritis risk. Immunol. Lett. 162: 207-211.http://dx.doi.org/10.1016/j.imlet.2014.08.018

Huang CM, Lo SF, Lin HC, Chen ML, et al. (2006). Correlation of oestrogen receptor gene polymorphism with gouty arthritis. Ann. Rheum. Dis. 65: 1673-1674.http://dx.doi.org/10.1136/ard.2005.051375

Hussain S, Iqbal T, Sadiq I, Feroz S, et al. (2015). Polymorphism in the IL-8 gene promoter and the risk of acne vulgaris in a Pakistani population. Iran J. Allergy Asthma Immunol. 14: 443-449.

Kim YS, Kim Y, Park G, Kim SK, et al. (2015). Genetic analysis of ABCG2 and SLC2A9 gene polymorphisms in gouty arthritis in a Korean population. Korean J. Intern. Med. 30: 913-920.http://dx.doi.org/10.3904/kjim.2015.30.6.913

Genetics and Molecular Research 15 (4): gmr15048511 
Koensgen D, Bruennert D, Ungureanu S, Sofroni D, et al. (2015). Polymorphism of the IL-8 gene and the risk of ovarian cancer. Cytokine 71: 334-338. http://dx.doi.org/10.1016/j.cyto.2014.07.254

Liu H, Mao P, Xie C, Xie W, et al. (2015). Association between interleukin 8-251 T/A and $+781 \mathrm{C} / \mathrm{T}$ polymorphisms and glioma risk. Diagn. Pathol. 10: 138. http://dx.doi.org/10.1186/s13000-015-0378-x

Miao Z, Li C, Chen Y, Zhao S, et al. (2008). Dietary and lifestyle changes associated with high prevalence of hyperuricemia and gout in the Shandong coastal cities of Eastern China. J. Rheumatol. 35: 1859-1864.

Qing YF, Zhou JG, Zhang QB, Wang DS, et al. (2013). Association of TLR4 Gene rs2149356 polymorphism with primary gouty arthritis in a case-control study. PLoS One 8: e64845. http://dx.doi.org/10.1371/journal.pone.0064845

Ramis IB, Vianna JS, Gonçalves CV, von Groll A, et al. (2015). Polymorphisms of the IL-6, IL-8 and IL-10 genes and the risk of gastric pathology in patients infected with Helicobacter pylori. J. Microbiol. Immunol. Infect. S16841182(15)00721-5. [Epub ahead of print]

Richette P and Bardin T (2010). Gout. Lancet 375: 318-328. http://dx.doi.org/10.1016/S0140-6736(09)60883-7

Shi Y, Mucsi AD and Ng G (2009). Monosodium urate crystals in inflammation and immunity. Immunol. Rev. 233: 203207.http://dx.doi.org/10.1111/j.0105-2896.2009.00851.x

Urano W, Yamanaka H, Tsutani H, Nakajima H, et al. (2002). The inflammatory process in the mechanism of decreased serum uric acid concentrations during acute gouty arthritis. J. Rheumatol. 29: 1950-1953.

Wallace SL, Robinson H, Masi AT, Decker JL, et al. (1977). Preliminary criteria for the classification of the acute arthritis of primary gout. Arthritis Rheum. 20: 895-900.http://dx.doi.org/10.1002/art.1780200320

Wang LF, Ding YJ, Zhao Q and Zhang XL (2015). Investigation on the association between NLRP3 gene polymorphisms and susceptibility to primary gout. Genet. Mol. Res. 14: 16410-16414.http://dx.doi.org/10.4238/2015.December.9.10

Wang Y, Bian ZM, Yu WZ, Yan Z, et al. (2010). Induction of interleukin-8 gene expression and protein secretion by C-reactive protein in ARPE-19 cells. Exp. Eye Res. 91: 135-142. http://dx.doi.org/10.1016/j.exer.2010.02.008

Wang Z, Wang C, Zhao Z, Liu F, et al. (2013). Association between $-251 \mathrm{~A}>\mathrm{T}$ polymorphism in the interleukin- 8 gene and oral cancer risk: a meta-analysis. Gene 522: 168-176.http://dx.doi.org/10.1016/j.gene.2013.03.066

Weaver AL (2008). Epidemiology of gout. Cleve. Clin. J. Med. 75: S9-12.http://dx.doi.org/10.3949/ccjm.75.Suppl 5.S9

Genetics and Molecular Research 15 (4): gmr15048511 